\title{
SAFETY OF STREET FOODS IN DEVELOPING COUNTRIES: AN OVERVIEW FROM PAKISTAN
}

\author{
Iram Asim \\ Department of Microbiology and Molecular Genetics, Faculty of Life Sciences, The Women University Multan 66000, Pakistan \\ Humaira Yasmeen* \\ Department of Microbiology and Molecular Genetics, Faculty of Life Sciences, The Women University Multan 66000, Pakistan \\ *Corresponding author \\ Department of Microbiology and Molecular Genetics, Faculty of Life Sciences, The Women University Multan 66000, Pakistan \\ Email: humaira.6127@wum.edu.pk
}

\begin{abstract}
Street food is one of the highlighted aspects in the cuisine of under developing countries. It contributes in the progress of socioeconomic improvement of nations. However regardless of its inexpensiveness, flavor and aroma it is linked with the variety of risks to consumers because of the way is it being prepared and served. There are noteworthy number of individuals who consumes street food on regular basis regardless of thinking about its safety. This review concludes the findings of the studies on the trends in street foods with relation to its consumption by consumers, risks associated and how can we be overcome such risks. This review recommends the awareness and enforcement of laws and community policies that should be helpful in minimizing the risks associated with street food along with the consumers and food vendors itself.
\end{abstract}

Keywords: Street food, consumers, hazard, risks, food safety

\section{Introduction}

Food is the basic need for human nourishment and sustenance. It provides energy and essential nutrients for better human growth. A balanced diet is required taken from nutritious food products to keep human body healthy (Vojkovska et al., 2017). It has been commonly observed that food and groceries are easily accessible in the streets on cheap rates than in a restaurant or in a supermarket. Such edibles are common among low socioeconomic group of society in both developed as well as developing countries. These foods attract common mob because of its savory taste preferred by indigenous public. The flavors are playing a significant role to attract masses for consumption of such eatables. This food not only feels good to taste but also provides nutrition so far. Hence, they have also become crucial for maintaining the food supply chain of the populations (Guraza 2018). The busy and scheduled life has worked well for the fast food industry. The conventional way of cooking has ended and the fast food points can be seen everywhere (Darwish 2018). Fresh vegetables are for sure rich sources of vitamins that are water soluble along with other nutrients essentials to improve the body health status and to reduce the risk of heart diseases. Nevertheless, when they are not cautiously cooked, they can be contaminated by pathogens and become harmful to health (Faour-Klingbeil et al., 2016).

\section{Street Food}


The term street food as defined by the food and agriculture organization (FAO) of the United Nations, in 1998 as "edibles that are ready to eat, and drinks made and retailed by hawkers and vendors particularly in road and rail network and roadsides". This definition was reiterated in 1996 by the World Health Organization (WHO) (Abrahale et al., 2019). It could be uncooked, fully or partially cooked, and hot, refrigerated or frozen. These ready-to-eat eatables can be animal food, plant food, fruits and vegetables, and bakery products ( $\mathrm{Ng}$ et al., 2013). Street food is a broad range of foods and beverages prepared and/or sold by vendors especially in streets about malls, trading centers and other public places for instant consumption or eating at a later without further processing. Street-vended edibles are subjected to contaminations because hawkers sell them in an open air and are often kept uncovered. Additionally, street vendors sell their foodstuff at doorsteps of their consumers. They often function at places such as bus stations, industrial areas, colleges, schools, marketplace roadsides and streets. Such places usually do not have the environment to meet requirements of food safety (Bereda $e t$ al., 2016). Food sold in streets is a significant part of our country's cuisine. These foods and drinks are making up local eating habits around the globe. Street food reflects the consumption habits of public living in big cities. About 2.5 billion people in the world intake street food every day. Mainly in Far East cuisine culture, production and selling of street vended food, has become a part of social life. People in developing countries use a significant amount of their budget to eat outside; street food has become a substitute eating trend. People in Latin America spend almost 30\% of their budget for street food (Sezgin and Şanlıer 2016).

\section{Types of Street Vended Foods}

There are different kinds of street food available across globe. These types vary from country to country according to their culture and geographical settings. Some street eatables are frequently found in every country such as salads, fried chicken, beef and gravy etc. The traditional street-vended foods in South East Asia i.e. Bangladesh include panipuri, bun, cake, sweet, sheek-kabab, laddu, singara, samosa (Hasan and Sikdar 2019). Pakistan has ranked sixth most populated country, having a population of about 180.1 million which is likely to spread 210.13 million by the year 2020. Approximately $20 \%$ of the population is surviving underneath the international scarcity streak of US\$ 1.25 each day. Illness load is massive with substandard parental and youngster wellbeing of situations in spite the element that, Pakistan spends $2.5 \%$ of its gross local products on healthiness (Akhtar et al., 2018). Health security position of Pakistani food is extremely detrimental as a widespread choice of eatables specifically street vended meals have been found to be microbiologically and chemically unhygienic. Universal drive to generate awareness for microbial pathogenesis and food borne diseases exclusively diarrhea, gastroenteritis and infection in lung tract are growing continually in Pakistan (Saeed et al., 2019).

\section{Changing Trends}

Globalization of food has increased the traveling of food. This facilitates the almost continuous availability of food, apart from of seasonal conditions (Meyerding et al., 2019). The rising consumption and easy approachability by smart phones have helped food retailers to publicize their occupation. Additionally, publicization through different mobile applications and social media also promote this eating culture. As a result, it is anticipated that the food industry of US $\$ 800$ million in 2015 is likely to magnify to US $\$ 985$ million by 2019 
(Shin et al., 2018).

\section{Consumer's Consumption}

Food choice and food eating is a complicated subject due to numerous factors such as food safety standards and hygiene, insecticide remains and toxic elements, infecting edibles, practice of seasonings, artificial flavors and colors. In urban society of developing countries street vended food is a chief source of nourishment. In established republics, consumers are more anxious about fitness while eating food (Smed and Jensen 2005). On the other hand, most consumers in developing countries may have little consciousness of food security standards but are not too much concerned about it (Asiegbu 2016). The family background and low socioeconomic status reflects their social variables, society's native habits or lifestyle. Recent studies have shown that customers mention fears as a chief stimulus for purchasing organic and local meals. As the argument grows on regarding the security of meals retailed in open air, manufacturing controllers and investigators alike have not completely grasped, which facet of street vended meals concerns, hypothetically disturb intake of such food and if such worries fluctuate amongst customers and non-customers of street vended food (Hiamey and Hiamey 2018). Awareness of risk and benefit has been a useful framework for elucidation of a consumer's purchasing behaviors. Apparent risk is the mutual effects of likelihood, the uncertainty involved in a buying decision while perceived benefit is described as a consumer's conviction about the degree to which people will become better off from the buying and/or use of an object. Previous studies have explored food-safety values in small level food enterprises, such as the food-truck business. Furthermore, consumers may be anxious that foods made by street vendors are normally nutritionally unwarranted and high in fat, because of using meager quality ingredients (Yoon and Chung 2018).

\section{Food Safety}

Food safety is the pledge that food will not be responsible of any harm or harmful effect to the customer when it is consumed. Street foods can cause a possible health risk to consistent consumers since food cooked and exposed to the open air for sale may get contaminated by pathogenic bacteria along with chemical toxicant (Ekhator et al., 2017). Foodborne bacterial pathogens are the main causative agents for human intestinal disease, in many countries. About 1.8 million people expired due to food-borne diarrhea every year in developing countries. Street foods are infected with bacteria and other microorganisms, making them dangerous for consumers' health (Younis et al., 2019). Street sold meals show an important part in meeting the food supplies of numerous individuals in under developed countries, and cherished by customers for their diversity, affordability and availability. As a result, uncleanness of street vended meat by pathogenic microbial strains is higher in the packed spaces, which often lack fundamental infrastructure and services, increasing the health risks (Shiningeni et al., 2019).

\section{Risk Factors}

\section{a) Agricultural Practices}

Farmers employ inorganic agrochemicals along with natural compost to expand the produce and growth of 
farm products, avoid struggle with weeds and sustain the worth by avoiding invasion by bugs and crop decomposition by microbes in the fields and throughout storing. The usage of such elements is well synchronized in advanced nations by the enforcement of acts and regulations which regulate their handling for agronomic preparations. Such regulations are to stop the remaining outcome of such substances on customers (Sezgin and Sanlier 2016). Nevertheless, contrary is the situation in under developing republics where growers do the extreme usage of chemicals to attain abundant harvests. Farmers in developing countries often employ easily manufactured, contemptible and patent expired chemicals. These chemicals are preserved in the eatable parts of fields, livestock and aquatic animals (Akhtar et al., 2018).

\section{b) Eminence of Uncooked Foods and Constituents}

Expedition for increase in revenue by the hawkers or the requirement to make street foods reasonable for the customers. Limited vendors make food with economical and hazardous ingredients that may be damaging to the healthiness of the customers. Approximately $56 \%$ of movable vendors employ unlabeled and uncovered condiments and flavors (Bereda et al., 2016). Researches shows that homebased cereal flour and condiments used in street edibles while cooking are contaminated with Bacillus cereus which was accountable for eruption of foodborne infections. Infected fish from chemically preserved and contaminated fishponds meat and milk from ill animals, practice of subnormal butchery facility and vegetables with heavy chemical remains are time and again used for food formulation in certain under developing nations (Shin et al., 2018).

\section{c) Food Preparation, Handling and Vending}

Though, the traditions and etiquettes street foods are being cooked, and vended exposed them to recontamination and spread of pathogenic bacteria and other food borne diseases. Majority of the meals for street vending are generally cooked in majority far before retailing. The extensive retaining period of more than six hours, occasionally at ambient temperature, were documented to be an ordinary aspect causative to food related sickness through increased growth of microbes. Researches have mentioned worrisome fears upon the hazardous exploitation street foods are showing to in the retailing surroundings (Ekhator et al., 2017). Street food sellers typically mark populated individual's transportation zones for the display of their foodstuffs to boost their sales. Street food retailing is a usual site in such zones as chief street corners, community spaces, industrial or building sites, bus along with train terminals and school areas. The vending carts are either stationary or mobile using exposed or covered simple assemblies such as display wooden tables, chop bars, push carts, aluminum platters or cutleries. Selling of a street meal along with major street in a under developing republic (Alimi 2016).

\section{d) Food Borne Illnesses}

Furthermore, lately approximation of food borne infection was completed and it was documented that majority (58\%) illnesses are due to Campylobacter spp. (9\%) nontyphoidal Salmonella spp. (11\%), and Clostridium perfringens (10\%) (Scallan et al., 2011). Food-borne disease (FBD) is an extensive and rising healthiness and economic dilemma. Recent improvisation in food manufacturing and proceeding exercises and ever-changing food traditions of the customer are vital aspects causing food related illness. Numerous documented pathogenic microbes 
are of notable apprehension nowadays. In developing countries, foodborne infection causes, according to an estimated, about 2.2 million demises every year, in which 1.9 million are offspring and this is in dire need of prevention (Imathiu 2017). Street vended food has both gram positive and gram-negative microbes. Gram-negative bacteria are beyond hazardous as disease causing microorganisms. Moreover, Gram- negative bacteria contains lipopolysaccharide in their external membrane. Lipopolysaccharide is an endotoxin which raise the acuteness of soreness. This soreness can be so acute that septic shock may happen. Gram-positive illness is usually less critical because of the reason that the human body does not contain peptidoglycan. Common gram- negative bacteria in street vended food is from genus Escherichia, Vibrio, Shigella, Salmonella, Campylobacter and Klebsiella (Faisal et al., 2017). Enterobacteriaceae is the family of gram- negative microbes employed as an indicator organism and defines the hygienic condition of edibles. The members of this family are notorious to cause well-being issues to humans. Such species are known as the coliform bacteria and are most of the time utilized as the fecal indicator organisms by food and water, because of their usual habitation which is the gastrointestinal tract (GIT) in animals and humans. Such microbial types have a capability of decay of food under the advantageous circumstances for their development and duplication (Rasmey et al., 2018). Symptoms of ailing caused by this family comprise nausea abdominal pain, headache, diarrhea and fever. Basics of salmonellosis include poultry, food products of animal origin and eggs. Foodborne Campylobacter is born in unboiled milk contaminated drinking water and raw or undercooked poultry (Fung et al., 2018).

Escherichia coli are related to unpasteurized milk, less cooked meat and fresh vegetables and fruits. Listeria contamination raise the peril of spontaneous stillbirths and abortions. Listeria is instigating in unpasteurized milk and in other dairy foodstuffs and numerous ready to eat (RTE) foods and has the ability to cultivate at refrigeration temperatures. Vibrio cholera poisons humans through contaminated food and water. Indications that appears in this infection are vomiting abdominal pain, and profuse watery diarrhea, which may result in severe dehydration and perhaps passing away. Vegetables, rice and few kinds of seafood have been concerned in cholera epidemics (Fung $e t$ al., 2018). Many studies have also detected L. monocytogenes in fresh food product samples and even in some unprocessed vegetables (Zhu et al., 2018). Probable health hazards are related with infectivity of food by Pseudomonas spp., Salmonella typhi, Escherichia coli, Proteus spp., Staphylococcus aureus during cooking while preparation and other dealing phases (Tambekar et al., 2008). In these 10 years, we have observed a thrilling increment in both the amount and total sum of microbial pathogens showing resistance to variety of antimicrobial agents. Organizations like the World Health Organization (WHO), The European Centre for Disease Prevention and Control (ECDC) and US Centers for Disease Control and Prevention (CDC) the believe such illnesses are triggered by multidrug resistant (MDR) microbes as intimidating and causing chief community health anxieties, globally (Roca et al., 2015).

Studies in Burkina Faso informed that Salmonella enterica taken from meat and several foods is resistant to antibiotics that are usually used like amoxicillin/clavulanic acid, aztreonam, cephalothin, cefepime, ceftriaxone, gentamicin, chloramphenicol, tetracycline, nalidixic-acid and ciprofloxacin (Darwish 2018). A study in Benin showed that $15.18 \%$ of $S$. aureus stains isolated from street vended food were immune to methicillin, kanamycin, gentamycin, tobramycin, and erythromycin. Moreover, the Salmonella species isolated from foods vended in Addis Ababa were not resistant to most of the drug. In a similar study, the isolated Shigella species revealed that multiple 
drug resistance patterns against ampicillin, trimethoprim sulpha methoxazole, chloramphenicol, streptomycin and tetracycline (Eromo et al., 2016).

\section{Recommendations}

Street food sold by vendors and hawkers plays a significant part of socioeconomic events in under developing republics. Its importance is encouraged by the capacity of business tangled, providing of ready to eat foodstuffs and jobs for the seething public along with the series of the dealings (Akhtar et al., 2018). The advantages and positive influence of street meals business to the markets of under developing nations provoked suggestions from investigators but with the condition of ensuring the better health surroundings for consumption (Shiningeni $e t$ al., 2019). Researchers have suggested that cautious method to the threats of street food should be initiated from decent agronomic attempts and pervade the entire series of the trading. It was observed that strategies and guidelines for harmless and healthy street meals business seems to be a lot unprotected in majority of the emerging states and in a few republics these safety measures don't exist. Therefore, reforming of the policies and complete enforcement would for sure make a noteworthy decrease in the risks of intake of street meals. These would encourage energetic contribution of all participants in street meals business like managements, street meal retailers, consumers, companies, and community consortia. Levitation on the responsiveness on the distasteful street foodstuffs retailing through media and audience participatory programs is one way of dealing with unhygienic food trading. Recruiting of specialists of nourishment and healthiness linked fields to generate proper plans for the need of managing of street meals vending and trade (Meyerding et al., 2019). Hazard awareness of food borne diseases along with hygienic standards should be given to street vendors and shopkeepers. Little understanding of food borne diseases hazard can cause a rational illusion, since such facts does not incorporate the numerous outcomes of hazards.

\section{Acknowledgment}

This research did not receive any funding.

\section{Conflict of Interest}

The authors declare no conflict of interest.

\section{References}

Vojkovska, H.; Myskova, P.; Gelbicova, T.; Skockova, A.; Kolackova, I. \& Karpiskova, R. 2017. Occurrence and characterization of food-borne pathogens isolated from fruit, vegetables and sprouts retailed in the Czech Republic. Food Microbiology, 63: 147-152.

Guraza, A.; Prabhusaran, N.; Lakshmi, K. \& Uma, A. 2018. Analysis of bacteriological profile of street vended foods and understand the practice of food handling hygiene among vendors. International Journal of Recent Scientific Research, 9: 27394- 27399.

Darwish, A. Z. M. 2018. Foodborne pathogens of fast food and ready-to-eat foods in Tabuk city and evaluating hazard for food quality. International Journal of Healthcare and Biomedical Research, 6: 149-158.

Faour-Klingbeil, D.; Kuri, V. \& Todd, E. 2016. The transfer rate of Salmonella typhimurium from contaminated 
parsley to other consecutively chopped batches via cutting boards under different food handling scenarios. Food Research International, 89: 495-503.

Abrahale, K.; Sousa, S.; Albuquerque, G.; Padrao, P. \& Lunet, N. 2019. Street food research worldwide: A scoping review. Journal of Human Nutrition and Dietetics, 32: 152-174.

Ng, Y. F.; Wong, S. L.; Cheng, H. L.; Yu, P. H. F. \& Chan, S. W. 2013. The microbiological quality of ready-to-eat food in Siu Mei and Lo Mei shops in Hong Kong. Food Control, 34: 547-553.

Bereda, T. W.; Emerie, Y. M.; Reta, M. A. \& Asfaw, H. S. 2016. Microbiological safety of street vended foods in Jigjiga City, Eastern Ethiopia. Ethiopian Journal of Health Sciences, 26: 163-172.

Sezgin, A. C. \& Şanlıer, N. 2016. Street food consumption in terms of the food safety and health. Journal of Human Sciences, 13: 4072-4083.

Hasan, M. \& Sikdar, B. 2019. Screening of antimicrobial, cytotoxic and pesticidal activities of Coccinia grandis (L.) Voigt. Journal of Microbiology, Biotechnology and Food Sciences, 584-588.

Akhtar, R. W.; Hannan, A.; Saleem, S.; Qaisar, A. \& Jahan, S. 2018. Frequency of vancomycin resistant Staphylococcus aureus among clinical isolates of MRSA collected from tertiary care hospitals of Lahore, Pakistan. Pakistan Armed Forces Medical Journal, 68: 580-584.

Saeed, H. M. A.; Abdullah, M.; Syed, A.; Anjum, A.; Manzoor, M.; Shahid, A. \& Pervaiz, N. 2019. Safety assessment of some food products with reference to adulteration in Faisalabad, Punjab, Pakistan. Discovery Science, 15: $1-15$.

Meyerding, S. G.; Trajer, N. \& Lehberger, M. 2019. What is local food? The case of consumer preferences for local food labeling of tomatoes in Germany. Journal of Cleaner Production, 207: 30-43.

Shin, Y. H.; Kim, H. \& Severt, K. 2018. Antecedents of consumers' intention to visit food trucks. Journal of Foodservice Business Research, 21: 239-256.

Smed, S. \& Dejgaard Jensen, J. 2005. Food safety information and food demand. British Food Journal, 107: 173-186.

Asiegbu, C. V.; Lebelo, S. L. \& Tabit, F. T. 2016. The food safety knowledge and microbial hazards awareness of consumers of ready-to-eat street-vended food. Food Control, 60: 422-429.

Hiamey, S. E. \& Hiamey, G. A. 2018. Street food consumption in a Ghanaian Metropolis: The concerns determining consumption and non-consumption. Food Control, 92: 121-127.

Yoon, B. \& Chung, Y. 2018. Consumer attitude and visit intention toward food-trucks: Targeting millennials. Journal of Foodservice Business Research, 21: 187- 199.

Ekhator, O. C.; Udowelle, N. A.; Igbiri, S.; Asomugha, R. N.; Igweze, Z. N. \& Orisakwe, O. E. 2017. Safety evaluation of potential toxic metals exposure from street foods consumed in Mid-West Nigeria. International Journal of Environmental Research and Public Health, 1-20.

Younis, R. I.; Nasef, S. A. \& Salem, W. M. 2019. Detection of Multi-Drug Resistant Food- borne bacteria in readyto-eat meat products in Luxor city, Egypt. SVU International Journal of Veterinary Sciences, 2: 20-35.

Shiningeni, D.; Chimwamurombe, P.; Shilangale, R. \& Misihairabgwi, J. 2019. Prevalence of pathogenic bacteria in street vended ready-to-eat meats in Windhoek, Namibia. Meat Science, 148: 223-228.

Alimi, B. A. 2016. Risk factors in street food practices in developing countries: A review. Food Science and Human Wellness, 5: 141-148. 
Scallan, E.; Hoekstra, R. M.; Angulo, F. J.; Tauxe, R. V.; Widdowson, M. A. \& Roy, S. L. 2011. Foodborne illness acquired in the United States-major pathogens. Emerging Infectious Diseases, 17: 7-15.

Imathiu, S. Street vended foods: potential for improving food and nutrition security or a risk factor for foodborne diseases in developing countries? Current Research in Nutrition and Food Science 2017, 5, 55-65.

Faisal, S. M. W.; Alam, A. K. \& Sajed, M. N. 2017. Isolation and identification of gram- negative bacteria from street-vended sauce and brand sauce in Dhaka city to evaluate their safety margin. Journal of Pharmaceutical Innovation, 6: 68-72.

Rasmey, A. H. M.; Desoki, S. G. \& Deabes, M. 2018. Isolation, characterization and antibiotics susceptibility ofglucuronidase producing Escherichia coli and other enteric bacteria from ground beef. African Journal of Biotechnology, 17: 29-36.

Fung, F.; Wang, H. S. \& Menon, S. 2018. Food safety in the $21^{\text {st }}$ century. Biomedical Journal, 41: 88-95.

Zhu, Z.; Cai, H. \& Sun, D. W. 2018. Titanium dioxide $\left(\mathrm{TiO}_{2}\right)$ photocatalysis technology for non-thermal inactivation of microorganisms in foods. Trends in Food Science and Technology, 75: 23-35.

Tambekar, D. H.; Jaiswal, V. J.; Dhanorkar, D. V.; Gulhane, P. B. \& Dudhane, M. N. 2008. Identification of microbiological hazards and safety of ready-to-eat food vended in streets of Amravati City, India. Journal of Applied Biosciences, 7: 195-201.

Roca, I.; Akova, M.; Baquero, F.; Carlet, J.; Cavaleri, M.; Coenen, S. \& Kahlmeter, G. 2015. The global threat of antimicrobial resistance: science for intervention. New Microbes and New Infect, 6: 22-29.

Eromo, T.; Tassew, H.; Daka, D.; Kibru, G. 2016. Bacteriological quality of street foods and antimicrobial resistance of isolates in Hawassa, Ethiopia. Ethiopian Journal of Health Sciences, 26: 533-542. 